\title{
How collaboration in therapy becomes therapeutic: The therapeutic collaboration coding system
}

\author{
Eugénia Ribeiro'*, António P. Ribeiro', Miguel M. Gonçalves', \\ Adam O. Horvath ${ }^{2}$ and William B. Stiles ${ }^{3}$ \\ 'School of Psychology, University of Minho, Braga, Portugal \\ ${ }^{2}$ Faculty of Education Counseling Psychology Program, Simon Fraser University, \\ Burnaby, British Columbia, Canada \\ ${ }^{3}$ Department of Psychology, Miami University, Oxford, Ohio, USA
}

\begin{abstract}
Background. The quality and strength of the therapeutic collaboration, the core of the alliance, is reliably associated with positive therapy outcomes. The urgent challenge for clinicians and researchers is constructing a conceptual framework to integrate the dialectical work that fosters collaboration, with a model of how clients make progress in therapy.
\end{abstract}

Aim. We propose a conceptual account of how collaboration in therapy becomes therapeutic. In addition, we report on the construction of a coding system - the therapeutic collaboration coding system (TCCS) - designed to analyse and track on a moment-by-moment basis the interaction between therapist and client. Preliminary evidence is presented regarding the coding system's psychometric properties. The TCCS evaluates each speaking turn and assesses whether and how therapists are working within the client's therapeutic zone of proximal development, defined as the space between the client's actual therapeutic developmental level and their potential developmental level that can be reached in collaboration with the therapist.

Method. We applied the TCCS to five cases: a good and a poor outcome case of narrative therapy, a good and a poor outcome case of cognitive-behavioural therapy, and a dropout case of narrative therapy.

Conclusion. The TCCS offers markers that may help researchers better understand the therapeutic collaboration on a moment-to-moment basis and may help therapists better regulate the relationship.

\section{Practitioner Points}

- To promote therapeutic collaboration.

\footnotetext{
* Correspondence should be addressed to Eugénia Ribeiro, School of Psychology, University of Minho, 47 I0 Braga, Portugal (e-mail: eugenia@psi.uminho.pt).
} 
- To facilitate regulation of therapeutic relationship

- To facilitate therapeutic change.

Therapeutic alliance is 'incontrovertibly the most popular researched element of the therapeutic relationship today' (Norcross, 2010, p. 120). Strength of the alliance is arguably the best and most reliable predictor of outcomes (Horvath \& Bedi, 2002; Horvath, Del Re, Fluckinger, \& Symonds, 2011; Horvath \& Symonds, 1991; Norcross, 2002; Wampold, 2001) and is generally considered one of the most important common factors in therapy (Lambert, 2004; Norcross \& Goldfried, 2005; Wampold, 2001). It has been argued that the alliance, at its core, is best understood as the quality and strength of the collaborative relationship between client and therapist (Hatcher \& Barends, 2006).

Definitions of collaboration differ across theoretical accounts (Horvath et al., 2011) but each formulation captures the elements of shared responsibility for deciding treatment goals and planning activities, active involvement with the therapist's proposals, compliance and participation in therapy tasks, and affinitive, cooperative, and engagement behaviours (Boardman, Catley, Grobe, Litle, \& Ahlumalia, 2006; Colli \& Lingiardi, 2009; Tyron \& Winograd, 2002). Safran and Muran $(2000,2006)$ argued that it is conceptually more helpful to think in terms of negotiation rather than collaboration, since 'the idea that the alliance is negotiated between the therapist and patient on an ongoing basis highlights the fact that the alliance is not a static variable that is necessary for the therapeutic intervention to work but rather a constantly shifting, emergent property of the therapeutic relationship' (p. 288). Similarly, Hatcher (1999) emphasized, collaboration is 'a joint achievement of the therapeutic dyad, an emergent property that depends on the effective meshing of individual patient and therapist contributions, contributions to which it cannot however simply be reduced [to one side of the therapeutic dyad]' (p. 418, emphasis added). Our view of collaboration captures both Safran and Muran's and Hatcher's uses of the notion of emergent property.

In a literature review on therapeutic collaboration, Lepper and Mergenthaler (2007), referred to several studies that 'suggest that there is a specific quality of communicative action that is of particular clinical value' (p. 557) such as the process of coordination (Westerman, 1998), or complementarity (Tracey, 1993). But, the authors highlighted, 'exactly what happens at the level of the turn-by-turn interaction between therapist and patient remains understudied' (p. 557). In order to fill this gap, Lepper and Mergenthaler (2007) developed an analytical strategy to study the therapeutic interaction that integrated the Therapeutic Cycles Model (Lepper and Mergenthaler, 2005, 2007; Mergenthaler, 1996) and Conversation Analysis (e.g., Sacks, Schegloff, \& Jefferson, 1974). Using this strategy they found, in a series of case studies, a correlation between topic coherence, as a marker collaborative rapport, and periods of affective and cognitive engagement (Lepper \& Mergenthaler, 2005, 2007, 2008). In accord with Lepper and Mergenthaler (2007), we argue that it is important to focus on the interactive microprocesses involved in the development of collaboration and its contribution to client's change. We suggest that understanding how collaboration moves the therapy forward requires a conceptual framework that integrates the dialectical work that fosters collaboration with a model of how clients make progress in therapy. In this paper, we present such a conceptual framework. In addition, we report on our construction of a coding system - the therapeutic collaboration coding system (TCCS) - we developed to analyse and track the interaction between therapist and client on a moment-by-moment basis. Our goal in developing the TCCS was to provide a reliable means to assess the ongoing work of therapy in terms of our model. 
Our conceptual and methodological approach to assessing collaboration makes use of the concept of the therapeutic zone of proximal development (TZPD; see Leiman \& Stiles, 2001). The TZPD is an extension of Vygotsky's (1978) concept of the zone of proximal development (ZPD). Briefly, the TZPD can be understood as a region within a developmental sequence that clients pass through in successful therapy. From this perspective, therapeutic work is productive when the therapy dialogue takes place within the client's TZPD. Therapeutic interventions within the TZPD are likely to succeed, whereas interventions outside it are likely to fail. The TZPD itself shifts to higher levels as therapeutic progress is made.

\section{A conceptual account of how collaboration becomes therapeutic}

The TCCS bridges and integrates two theories of change in psychotherapy: Stiles' assimilation model (Stiles, 2001, 2011) and the narrative framework of Gonçalves \& Stiles (2011), specifically the Innovative Moments Model (Gonçalves, Matos, \& Santos, 2009).

\section{Assimilation and self-narratives}

The assimilation model is a theory of psychological change that conceives the self as a community of internal voices, which represent traces of the person's experiences or ways of being in the world. Constellations of similar or related experiences become linked or assimilated and form a community of voices. The community is experienced by the person as their usual sense of self, personality, or centre of experience. The model suggests that the disconnection of certain voices from the community underlies many forms of psychological distress. Such problematic voices may be assimilated through psychotherapeutic dialogue by building meaning bridges, that is, words or other signs that can represent, link, and encompass the previously separated voices and thereby form a new configuration (Stiles, 2011). Self-narratives are meaning bridges that organize and interlink disparate life experiences, providing orderly and smooth access to them (Osatuke et al., 2004; Stiles, 2011), selecting, combining, and organizing them into selfidentities (Gonçalves et al., 2009; McAdams, 2001; White \& Epston, 1990). A client's initial (presenting) self-narrative may be maladaptive because it fails to acknowledge important parts of the client's life experience. In other words, a voice may become problematic to the rest of the self if the self-narrative is too rigid and excludes such voice from the community of voices (Ribeiro, Bento, Salgado, Stiles, \& Gonçalves, 2011).

Consistent with the assimilation model, we construe positive change in psychotherapy as a developmental process in which clients move from maladaptive self-narrative to a more functional self-narrative. That is, they gradually shift from ways of understanding and experiencing that are dysfunctional - because they exclude important internal voices - to ways that incorporate the previously excluded voices.

\section{Innovative moments}

From a narrative perspective, instances in which non-dominant voices express themselves, constitute exceptions to the dominant self-narrative and are identified as innovative moments, IMs (see Gonçalves et al., 2009; see Gonçalves, Ribeiro, Mendes, Matos, \& Santos, 2011, for a review of IMs findings across different therapeutic approaches). Expressions by non-dominant voices (IMs) can disrupt the dominance of the current community of voices, at least temporarily, opening an opportunity for new meaning 
bridges to develop. Thus the accumulation of IMs moves therapy forward, through the development of a revised, alternative self-narrative.

Clients usually come to therapy with a limited tolerance or capacity for experiencing the world in alternative ways, and therapists seek to provide a climate in which new experiences or IMs can be tolerated and considered. Accordingly, we conceptualize therapeutic activities as having two main components. First, therapists seek to support their clients and help them feel safe. This usually involves communication of an understanding and accepting of the client's experience within his or her usual perspective (the client's currently dominant but maladaptive self-narrative). Second, therapists may challenge the dominant maladaptive self-narratives, promoting the occurrence of IMs and revisions in clients' usual perspectives. We suggest that these components of interactive collaboration are ideally maintained in a dynamic balance within the therapeutic relationship; that is, the therapist must work within a zone in which the client not only feels safe but is also able to experience IMs. Too much emphasis on safety may overlook opportunities for revision of the maladaptive self-narrative, whereas too much emphasis on challenge may stimulate excessive anxiety, fostering resistance.

\section{Therapeutic zone of proximal development}

We conceptualize progress in therapy as a developmental continuum. In successful therapy, clients move from their initial maladaptive self-narrative (i.e., interpreting reality in a way congruent with it), to gradually increasing the capacity to accommodate IMs. In this process, the previous self-narrative is transformed into a new one better suited to the challenges they face. The Assimilation of Problematic Experiences Sequence (APES; Brinegar, Salvi, Stiles, \& Greenberg, 2006; Caro Gabalda \& Stiles, 2012) illustrates the sort of therapeutic developmental continuum we have in mind, proposing that clients appear to follow a regular developmental sequence of recognizing, formulating, understanding, and eventually, resolving the problematic (i.e., non-assimilated) experiences that brought them into treatment.

With Leiman and Stiles (2001), we extend Vygotsky's (1978) concept of the ZPD, from children's cognitive development to therapeutic development. Vygotsky (1978) defined the ZPD as 'the distance between [a child's] actual developmental level as determined by independent problem solving, and the level of potential development as determined through problem solving under adult guidance or in collaboration with more capable peers' (p. 86). In agreement with Leiman and Stiles (2001), we suggest that therapists facilitate change by working within a Therapeutic Zone of Proximal Development (TZPD) along the therapeutic developmental continuum. The TZPD is defined as the space between the client's current capacity to accommodate the IMs (usually very limited when clients ask for help, given the rigidity of the maladaptive self-narrative) and a potential capacity that can be reached in collaboration with the therapist. As Leiman and Stiles (2001) pointed out, the TZPD is a way of describing joint activity, not a capacity of client, nor a variable reflecting stable characteristics of the dyad. This point of optimal balance between support and challenge changes systematically as therapy progresses.

\section{Semiotic mediation and internalization}

In Vygotsky's account, as well as in our proposal, the notion of ZPD is descriptive, not explicative - it indicates the difference between two developmental levels - clients' 
actual and potential developmental level. The cause of this difference is not the ZPD but other kinds of psychological process, such as semiotic mediation and internalization.

When therapist and client talk to each other, they draw on the vast stock of linguistic (and non-linguistic) signs for their joint exploration. The signs become mediators when the other recognizes their meaning and responds; that is, client and therapist share their experiences by using signs they both understand. They thereby expand the meaning of the signs to incorporate the experiences they have shared with each other (Stiles, 2011). Signs that share experiences may be described as interpersonal meaning bridges and occur within the TZPD. Building interpersonal meaning bridges is facilitated by therapists' and clients' mentalizing (Dimaggio, Carcione, Salvatore, Semerari, \& Nicolò, 2010; Dimaggio et al., 2011; Fonagy, Bateman, \& Bateman, 2011; Liotti \& Gilbert, 2011), that is, 'attending to mental states in self and others [clients] and interpreting behaviour accordingly' (Alen, Fonagy, \& Bateman, 2008, p.41).

Vygotsky (1978) argued that signs developed in interpersonal communication become available for intrapersonal communication through the developmental process of internalization. Hence, in therapy, formulations of the problem and strategies jointly explored (regardless of the therapeutic modality) may turn into client resources for building intrapersonal meaning bridges, which may ultimately result in the emergence of an alternative self-narrative. Along these lines, we may think of collaboration as a therapeutic agent per se.

\section{Therapist strategies for facilitating change: Supporting versus challenging}

Therapeutic change is facilitated by using strategies that help clients move from their actual developmental level towards their potential developmental level. To do so, therapists must take into account the client's TZPD at a given moment; specifically the client's current stage of change (e.g., assimilation level) and the client's mentalizing capacity (i.e., capacity to make sense of the therapist's comments).

As change takes place, the TZPD moves; that is, what was formerly a potential level becomes an actual level and extends the client's potential level towards greater capacity to accommodate IMs. Therapists do not have a prior $i$ knowledge about clients' potential level, but following an implicit principle of push where it moves, they can adjust when and what they support (e.g., work at or near the client's current assimilation level) or challenge (e.g., work slightly beyond client's current assimilation level) to help clients advance along the developmental continuum.

Supporting consists of working closer to the actual TZPD level, that is, confirming and elaborating upon client's perspective on his or her experience. We hypothesize that when the client sees that his or her perspective is supported by the therapist, he or she will experience a sense of safety.

Supporting is usually focused on the current self-narrative, which is often the dominant maladaptive self-narrative. For example, when therapist tries to empathically understand the role, the problem plays in the client's life from the client's perspective. Alternatively, supporting may be focused on emerging IMs, for example, when therapist tries to empathically understand how IMs emerged. A focus on the current dominant view, however, is likely safer for the client than a focus on the IM. Focusing on IM could amplify the contrast with the current self-narrative, triggering a sense of contradiction or self-discrepancy, creating dysphoric feelings of unpredictability and uncontrollability (Arkowitz \& Engle, 2007). 


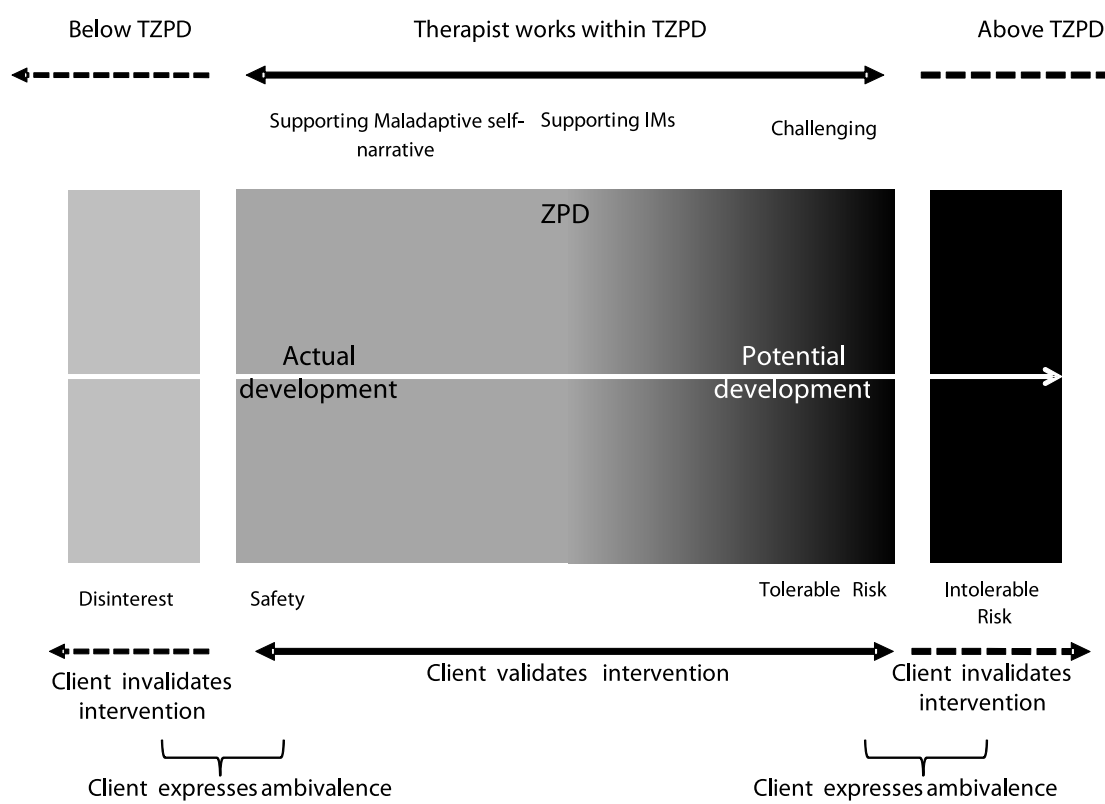

Figure I. Segment of the therapeutic developmental continuum showing the therapeutic zone of proximal development (TZPD).

Challenging consists of working closer to the TZPD potential level, that is, moving beyond client's current maladaptive self-narrative, which may encourage the client to revise it, generating an experience of risk (Ecker \& Hulley, 2000; Engle \& Arkowitz, 2008; Engle \& Holiman, 2002; Gonçalves et al., 2011; Kelly, 1955; Mahoney, 1991; Ribeiro \& Gonçalves, 2010).

From the perspective of the mentalization theory, the sense of safety is a pre-requisite for mentalizing (Liotti \& Gilbert, 2011). Mentalizing, in turn, fosters clients' capacity to tolerate and assimilate challenging interventions and move forward within the TZPD.

\section{Levels of risk and client validation or invalidation of interventions}

Clients' responses to therapeutic interventions reflect the level of risk they experience, and the level of risk depends on the relation of the intervention to their current TZPD. The relations among therapist interventions, the current TZPD, client experience, and client responses are diagrammed in Figure 1. The intersection of these possibilities provides the conceptual basis for the TCCS.

We use the clients' responses to distinguish those therapist's interventions that are validated from those that are invalidated. Validation refers to the client explicitly or implicitly accepting the therapist's invitation to look at his or her experience from the proposed (novel) perspective. In validating an intervention, a client's response may lag bebind the intervention on the therapeutic developmental continuum, respond at the same level of the intervention, or extend beyond the level of the intervention. Invalidation refers to a client declining an invitation to look at his or her experience from the new perspective offered by the therapist. Invalidation likely occurs when therapist's intervention does not respect client's level of change. Interventions that do not take into account client's mentalizing capacity may also generate invalidation responses. Our 
measure is built on the hypothesis that the client's validation or invalidation response indicates the position of the therapist's intervention in relation to the TZPD.

(1) If the intervention is below the lower limit of the TZPD (e.g., if the therapist intervenes at a level already solved) or if it is irrelevant to current problems, clients experience minimal risk, but they are also likely to experience disinterest. They typically invalidate the intervention, perhaps feeling that the therapist is being redundant (not getting anywhere) or off-topic.

(2) If the intervention is at the lower limit of the TZPD, clients experience ambivalence - they begin to accept the perspective proposed by the therapist but then take an opposite perspective. They thus tend to show mixed signs of validation and invalidation and are likely extend beyond the level proposed by the therapist, moving towards risk.

(3) If the intervention is within the TZPD and close to the client's actual level, clients experience a feeling of safety. They typically validate the intervention and may remain at, or extend beyond the level proposed by the therapist.

(4) If the intervention is within the TZPD but closer to the client's potential level, clients experience tolerable risk. Again, they typically validate the intervention and may lag behind or remain at the level proposed by the therapist.

(5) If the intervention is at the upper limit of the TZPD, clients experience ambivalence - they begin to accept the perspective proposed by the therapist but then take an opposite perspective. They thus tend to show mixed signs of validation and invalidation and are likely to lag behind the proposed level, moving towards safety. Such behaviours characterize the return-to-the-problem marker in the Innovative Moments Model (Gonçalves, Mendes, Ribeiro, Angus, \& Greenberg, 2010; Gonçalves \& Ribeiro, 2012; Gonçalves et al., 2011); Ribeiro \& Gonçalves, 2010).

(6) If the intervention is above the upper limit of the TZPD, clients experience intolerable risk. They typically invalidate therapist's intervention, for example by changing the subject, misunderstanding, or becoming defensive.

As noted before, the clients' TZPD constantly evolves throughout the therapeutic process, redefining its limits moment by moment. What was risky (closer to the potential level) for the client at a given moment may later become safe (closer to actual level). On the other hand, as setbacks inevitably occur (Caro Gabalda \& Stiles, 2009, 2012), what seemed safe at one moment may become risky in the next.

\section{The therapeutic collaboration coding system (TCCS)}

The TCCS grew from our theory of how therapy participants attempt to manage the therapeutic dialogue within the TZPD. The instrument was refined and validated through the analysis of 82 sessions of five clients: 41 sessions from of narrative therapy and 41 sessions of cognitive-behavioural therapy. The TCCS required two stages of category construction. At the first stage, it required categories and sub-categories of therapist intervention (Table 1) and client response (Table 2). At the second stage, it required categories of exchange (each comprising two speaking turns), as outlined in Table 3. 
Table I. Therapist intervention coding sub-categories

\begin{tabular}{|c|c|}
\hline Supporting sub-categories & Definitions \\
\hline Reflecting & $\begin{array}{l}\text { The therapist reflects the content; meaning or feeling present in the } \\
\text { client's words. He or she uses his/her or client's words but does not } \\
\text { add any new content in the reflection, asking for an implicit or explicit } \\
\text { feedback. }\end{array}$ \\
\hline Confirming & $\begin{array}{l}\text { The therapist makes sure he/she understood the content of the client's } \\
\text { speech, asking the client in an explicit and direct mode. }\end{array}$ \\
\hline Summarizing & $\begin{array}{l}\text { The therapist synthesizes the client's discourse, using his/her own and } \\
\text { client's words, asking for feedback (implicit or explicit) }\end{array}$ \\
\hline $\begin{array}{l}\text { Demonstrating } \\
\text { interest/attention }\end{array}$ & The therapist shows/affirms interest on client's discourse. \\
\hline Open questioning & $\begin{array}{l}\text { The therapist explores clients experience using open questioning. The } \\
\text { question opens to a variety of answers, not anticipated and/or linked to } \\
\text { contents that the client does not reported or only reported briefly. } \\
\text { This includes the therapist asking for feedback of the session or of the } \\
\text { therapeutic task. }\end{array}$ \\
\hline Minimal encouragement & $\begin{array}{l}\text { The therapist makes minimal encouragement of client's speech, repeating } \\
\text { client's words, in an affirmative or interrogative mode (ambiguous } \\
\text { expressions with different possible meanings are not codified, like a } \\
\text { simple "Hum... hum" or "ok"). }\end{array}$ \\
\hline Specifying information & $\begin{array}{l}\text { The therapist asks for concretization or clarification of the (imprecise) } \\
\text { information given by the client, using closed questions, specific focused } \\
\text { questions, asking for examples. }\end{array}$ \\
\hline
\end{tabular}

Challenging markers

Definitions

Interpreting

The therapist proposes to the client a new perspective over his or her perspective, by using his or her own words (instead of client words). There is, although, a sense of continuity in relation to the client's previous speaking turn,

Confronting

The therapist proposes to the client a new perspective over his or her perspective or questions the client about a new perspective over his or her perspective. There is a clear discontinuity (i.e., opposition) with in relation to the client's speaking turn.

Inviting to adopt a new perspective

Inviting to put into practice a new action

Inviting to explore hypothetical scenarios

The therapist invites (implicitly or explicitly) the client to understand a given experience in an alternative.

The therapist invites the client to act in a different way, in the session or out of the session.

The therapist invites the client to imagine hypothetical scenarios, that is, cognitive, emotional, and/or behavioural possibilities that are different from client's usual way of understanding and experiencing.

Changing level of analysis

The therapist changes the level of the analysis of the client's experience from the descriptive and concrete level to a more abstract one or vice versa.

Emphasizing novelty

The therapist invites the client to elaborate upon the emergence of novelty.

Debating client's beliefs The therapist debates the evidence or logic of the client's believes and thoughts.

Tracking change evidence The therapist searches for markers of change, and tries to highlight them. 
Table 2. Client response coding sub-categories

\begin{tabular}{ll}
\hline Validation sub-categories & \multicolumn{1}{c}{ Definitions } \\
\hline Confirming & $\begin{array}{c}\text { The client agrees with the therapist's intervention, but does not } \\
\text { extend it. } \\
\text { The client provides information according to therapist's specific } \\
\text { request. } \\
\text { The client not only agrees with the therapist intervention, but } \\
\text { expands it (i.e., going further). }\end{array}$ \\
Reformulating oneself perspective & $\begin{array}{r}\text { The client answers the therapist's question or reflects upon the } \\
\text { therapist's prior affirmation and, in doing so, reformulates his } \\
\text { or her perspective over the experience being explored. } \\
\text { The client attempts to clarify the sense of his or her response } \\
\text { to the therapist prior intervention or clarify the sense of the } \\
\text { therapist's intervention itself. }\end{array}$ \\
Clarifying &
\end{tabular}

Invalidation sub-categories

Definition

Expressing confusion

Focusing/persisting on the dominant maladaptive self-narrative

Defending oneself perspective and/or disagreeing with therapist's intervention

Denying progress

Self-criticism and/or hopelessness

Lack of involvement in response

Shifting topic

Topic/focus disconnection

Non meaningful storytelling and/or focusing on others' reactions

Sarcastic answer
Client feels confused and/or states his or her incapacity to answer the therapist's question.

Client persists on looking at a specific experience or topic from his or her standpoint.

Client defends his/her thoughts, feelings, or behaviour by using self-enhancing strategies or self-justifying statements.

Client states the absence of change (novelty) or progress.

Client is self-critical or self-blaming and becomes absorbed in a process of hopelessness (e.g., client doubts about the progress that can be made).

Client gives minimal responses to therapist's efforts to explore and understand client's experience.

Client changes topic or tangentially answers the therapist.

The client persists in elaborating upon a given topic despite the therapist's efforts to engage in the discussion of a new one.

Client talks in a wordy manner or overly elaborates non-significant stories to explain an experience and/or spends inordinate amount of time talking about other people.

The client questions therapist's intervention or is ironic towards therapist's intervention.

\section{Development of TCCS: Procedure for constructing categories}

Consensual definition of the problematic self-narratives and selection of passages involving client problems

First, the judges carefully read the entire therapy transcript. Next, they independently characterized the maladaptive self-narratives and then met and discussed their formulations. After this discussion, these maladaptive self-narratives were consensually defined and specified in writing, sticking as close as possible to the client's words and narrative structure, following Innovative Moments Coding System procedure (Gonçalves, Ribeiro, Mendes, et al., 2011). Judges selected only passages in which therapist and client were talking about the client's problems for classification. Passages in which therapist and 
client were not talking about client's problems - for example, talking about the weather or other external events - were coded as non-classifiable.

Interactive refinement of category definitions

In constructing categories, judges considered all passages in which therapist and client were talking about the client's problems using to the above-described types of therapist's intervention (supporting the maladaptive self-narrative, supporting IMs, or challenging) and client's response categories (validation, invalidation, or ambivalence).

After independently coding each session, the judges met to evaluate the reliability of the coding procedure and to identify differences in their ratings. Differences were resolved through discussion. During these meetings, the judges also discussed the procedures and criteria they used. Through this recursive procedure, the judges integrated the strengths of each other's approach, facilitating consensus on category definition (cf. Brinegar et al., 2006). This consensually derived version of the TCCS was audited by an external auditor who then met with the pair of judges to discuss his or her feedback. His or her role was one of 'questioning and critiquing' (Hill et al., 2005, p. 201).

During this interactive process, judges formulated data-driven sub-categories for therapist interventions (see Table 1) and client response (see Table 2). After deciding on the category of therapist interventions, the judges tried to define how the therapist did what they did. This process was guided by the question: 'How does the therapist support/challenge the client?' By the same token, after deciding on client response category, the judges tried to define how the client did what they did. This process was guided by the question: 'How does the client validate/invalidate the therapist's intervention?' The emergent sub-categories were discussed and named by the research team using the consensual method (Hill et al., 2005).

\section{Therapist's intervention categories}

The judges classified each therapist speaking turn in a supporting category or a challenging category (see Table 1). For supporting categories, they further decided whether it focused on the current (maladaptive) self-narrative or focused on the IMs, by assessing whether the previous clients speaking turn focused on the current (maladaptive) self-narrative or focused on the IMs.

\section{Client's response categories}

The judge classified each client speaking turn as a validation sub-category, an invalidation sub-category (see Table 2), or an ambivalence category. These categories were interpreted as reflecting the position of the exchange relative to the TZPD. Exchanges within the TZPD required a validation category. Exchanges outside of the TZPD required an invalidation category. Finally, exchanges at the limit of the TZPD required a validation category immediately followed by an invalidation category or vice versa.

\section{Development of TCCS: Types of therapeutic exchanges}

The articulation of therapist's intervention and client's response potentially defines a two-dimensional space that describes the position of the dyad relative to the TZPD. In 
Tables 3 and 4 and Figures 2-4, we describe the 15 alternative types of therapeutic exchanges that resulted from such articulation and their relation to the TZPD. The contents of the cells of Table 3 are hypothetical descriptions of the interplay between the two dimensions. They represent our theoretical expectation of how clients would respond to therapist interventions below, within, at the limit, or beyond the current TZPD.

The different types of therapeutic exchanges corresponding to the identified codes and their sequence were all present (see Table 4), except for supporting innovative moments - disinterest. Figures 2-4 give examples of the alternative classes of therapeutic exchanges. For the sake of clarity, these illustrative vignettes were constructed for a hypothetical client diagnosed with Major Depression whose dominant maladaptive selfnarrative was focused on the idea 'I should be a superman'. Within this self-narrative, sadness was regarded as weakness and followed by guilt.

\section{TCCS coding procedures}

The coding procedure requires analysis of the text by two judges unaware of the outcome status of the cases under analysis, along with and auditing process (Hill et al., 2005). Three steps are carried out in the process of coding using TCCS: (1) consensual definition of the problematic self-narratives and selection of passages involving client problems, (2) categorization of therapist's intervention and client's response, and (3) categorization of therapeutic exchanges.

Consensual definition of the problematic self-narratives and selection of passages involving client problems by the two judges

The first step of the process of coding consists of reading the transcript, watching the videos, or listening to the records of the data. Following this initial procedure, judges independently list the clients' problems (or themes of the problematic self-narrative) and then meet to discuss their comprehension of clients' maladaptive self-narratives. After this discussion, the dominant problematic self-narratives are consensually defined (as closely as possible to the client's discourse). This procedure sets the stage for the selection of passages involving client problems that will be subsequently coded.

\section{Categorization of therapist's intervention and client's response}

The TCCS unit of analysis is the speaking turn. Each client speaking turn and therapist speaking turn is evaluated in the context of the other's previous speaking turn (immediate context) and all previous client-therapist interaction during that session (overall context). The TCCS is a transcript-based method. However, audio or video recordings can be used to resolve difficult judgements by using paralinguistic and nonverbal information. It is important to note that the pair of judges meet after coding each session to conduct the reliability procedure (Cohen's kappa) and to note the differences in their perspectives on their coding. Whenever these are detected, they are resolved through consensual discussion/coding.

In coding of a validation category, judges further assess whether clients lag bebind the intervention on the therapeutic developmental continuum, respond at the same level as the intervention, or extend beyond the level of the intervention, according to the specific sub-categories of client's response (see Table 3). 


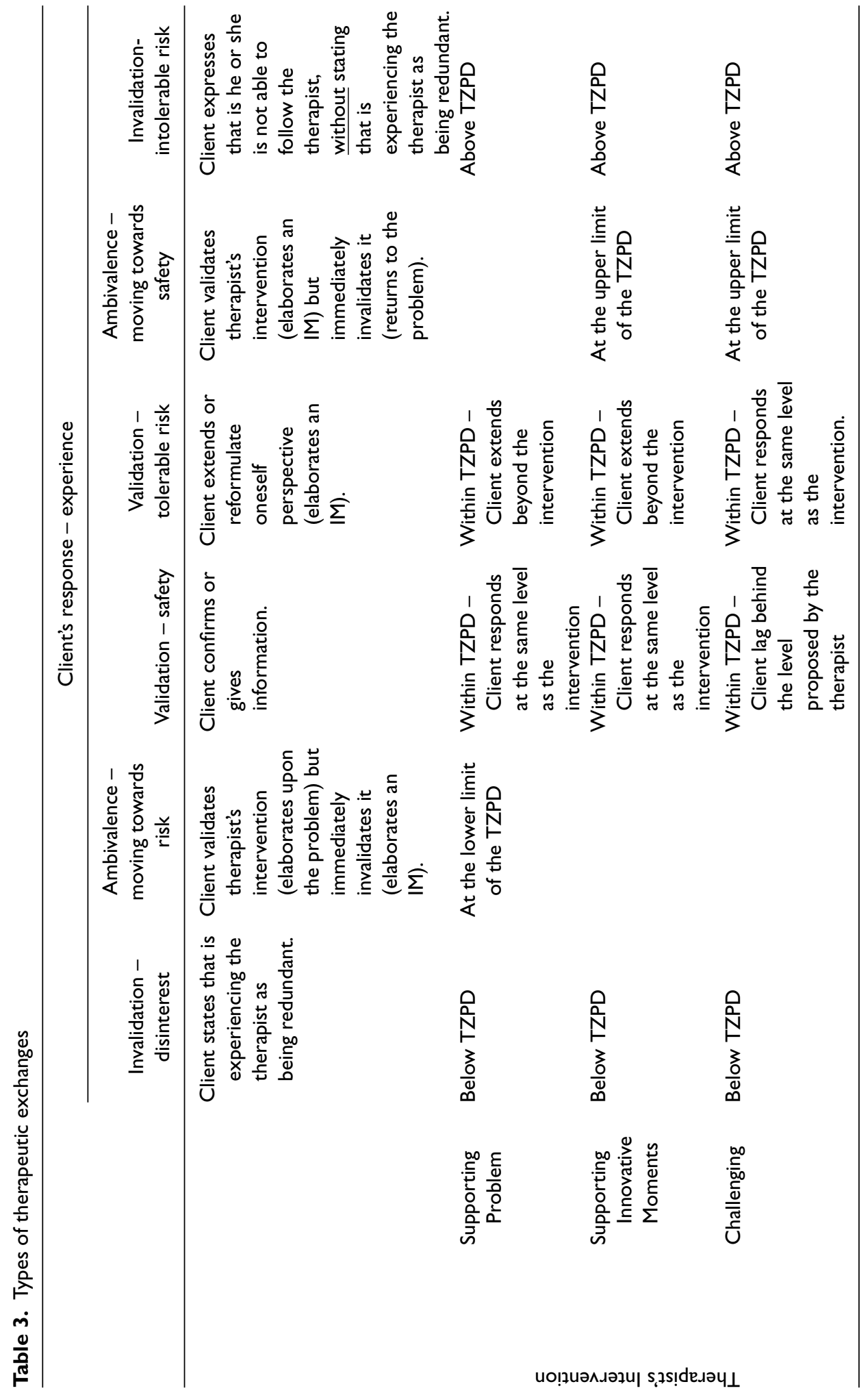




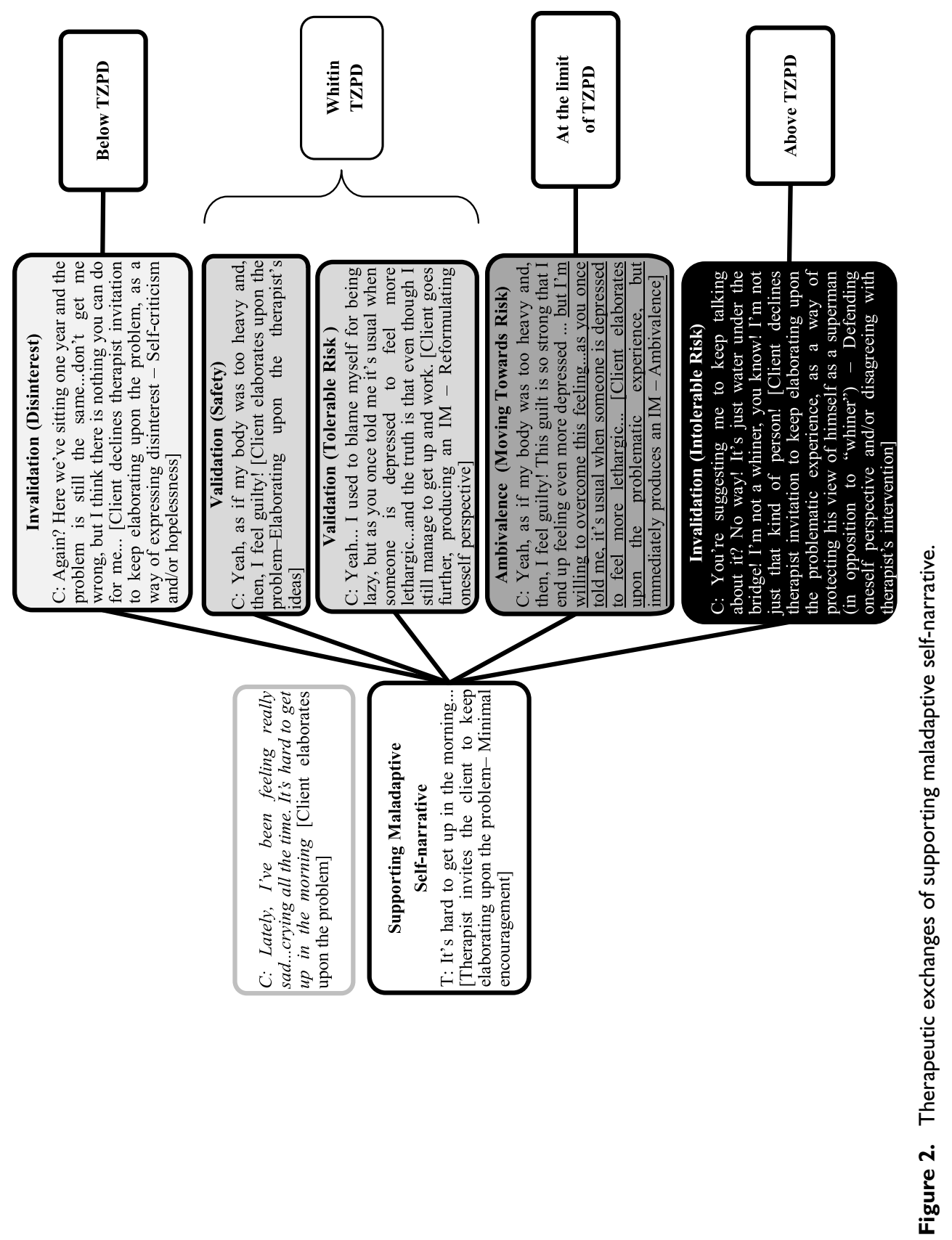


Table 4. Frequency of different types of therapeutic interchanges

\begin{tabular}{lr}
\hline Types of therapeutic interchanges & Frequency \\
\hline Supporting problem - disinterest & 2 \\
Supporting problem - safety & 1,563 \\
Supporting problem - tolerable risk & 236 \\
Supporting problem - moving towards risk & 38 \\
Supporting problem - intolerable risk & 69 \\
Supporting IMs - disinterest & 0 \\
Supporting IMs - safety & 986 \\
Supporting IMs - tolerable risk & 329 \\
Supporting IMs - moving towards safety & 62 \\
Supporting IMs - intolerable risk & 72 \\
Challenging - disinterest & 11 \\
Challenging - safety & 1,916 \\
Challenging - tolerable risk & 773 \\
Challenging - moving towards safety & 822 \\
Challenging - intolerable risk & 900 \\
Total & 7,779 \\
\hline
\end{tabular}

In coding an invalidation category, judges assess whether the therapist worked below the lower limit or above the upper limit of the TZPD. The distinctive feature of exchanges below the TZPD is the presence of markers that indicates the client experienced the therapist as being redundant.

\section{Categorization of therapeutic exchanges}

Using the precedent codes and their sequence, judges categorize therapeutic exchanges (each comprising two speaking turns) according to the taxonomy of therapeutic exchanges described in Table 3.

\section{Preliminary validation of the TCCS}

\section{Clients}

Five clients were randomly selected from our database. Each of them were diagnosed with Major Depression, using the Structured Clinical Interview for DSM-IV I (First, Spitzer, Gibbon, \& Williams, 1996). Two of the clients were good outcome cases (one of narrative therapy and another of cognitive-behavioural therapy), two of them were poor outcome cases (one of narrative therapy and another of cognitive-behavioural therapy), and one of the cases was a dropout case (narrative therapy). They were all white and females; their age ranged from 20 to 47 years (mean age 35.80 years).

\section{Therapists and therapy}

Three PhD students with 5 years of clinical experience participated as therapists. Two narrative therapists (one woman and one man) and one cognitive-behavioural therapist were trained and weekly supervised on respective therapeutic models. They all had 5 years of clinical experience. 


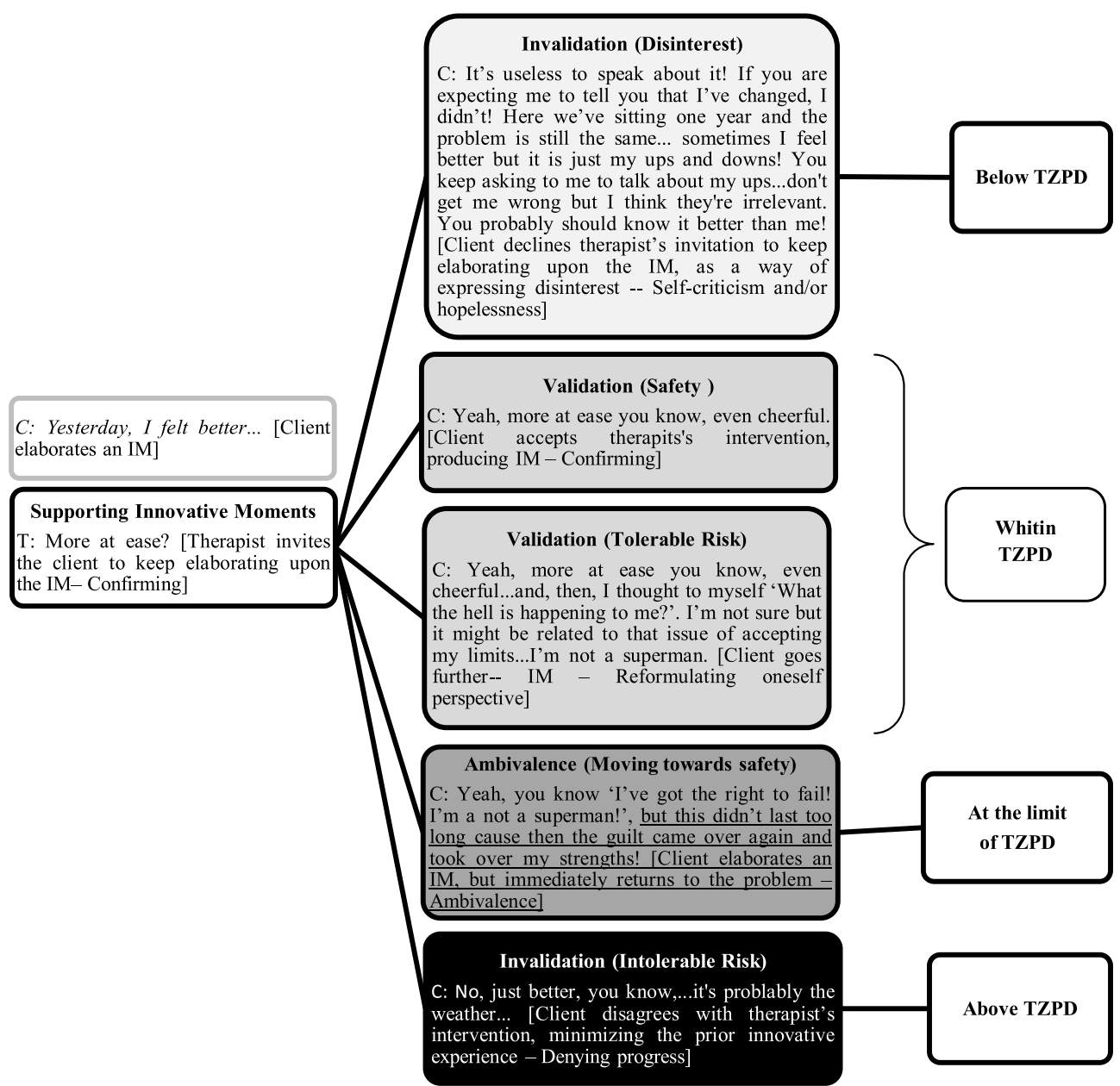

Figure 3. Therapeutic exchanges of supporting innovative moments.

\section{Judges and auditors}

Four masters students in clinical psychology and two PhD students in clinical psychology, previously trained and reliable on the TCCS (minimum Cohen's kappa value of .75) served as judges. A university faculty member in clinical psychology and a PhD student in clinical psychology served as auditors.

\section{Procedure}

To assess inter-judge reliability, four pairs of judges independently coded a subsample of 39 out of 82 psychotherapy sessions used to construct the TCCS (47.6\% of our sample). Sessions were coded in the order they occurred. At least $30 \%$ of the total speaking turns of the cases had been coded. 


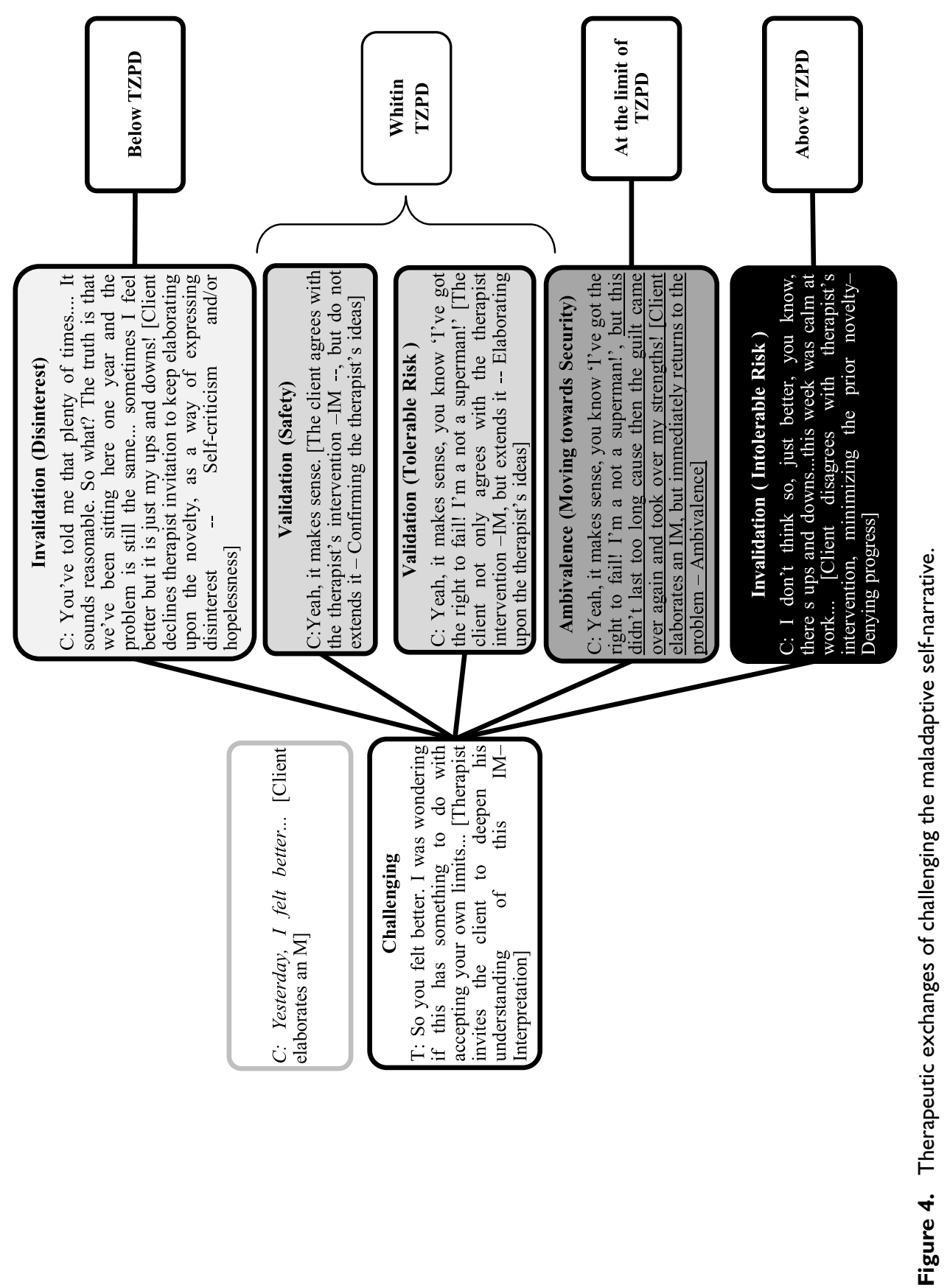




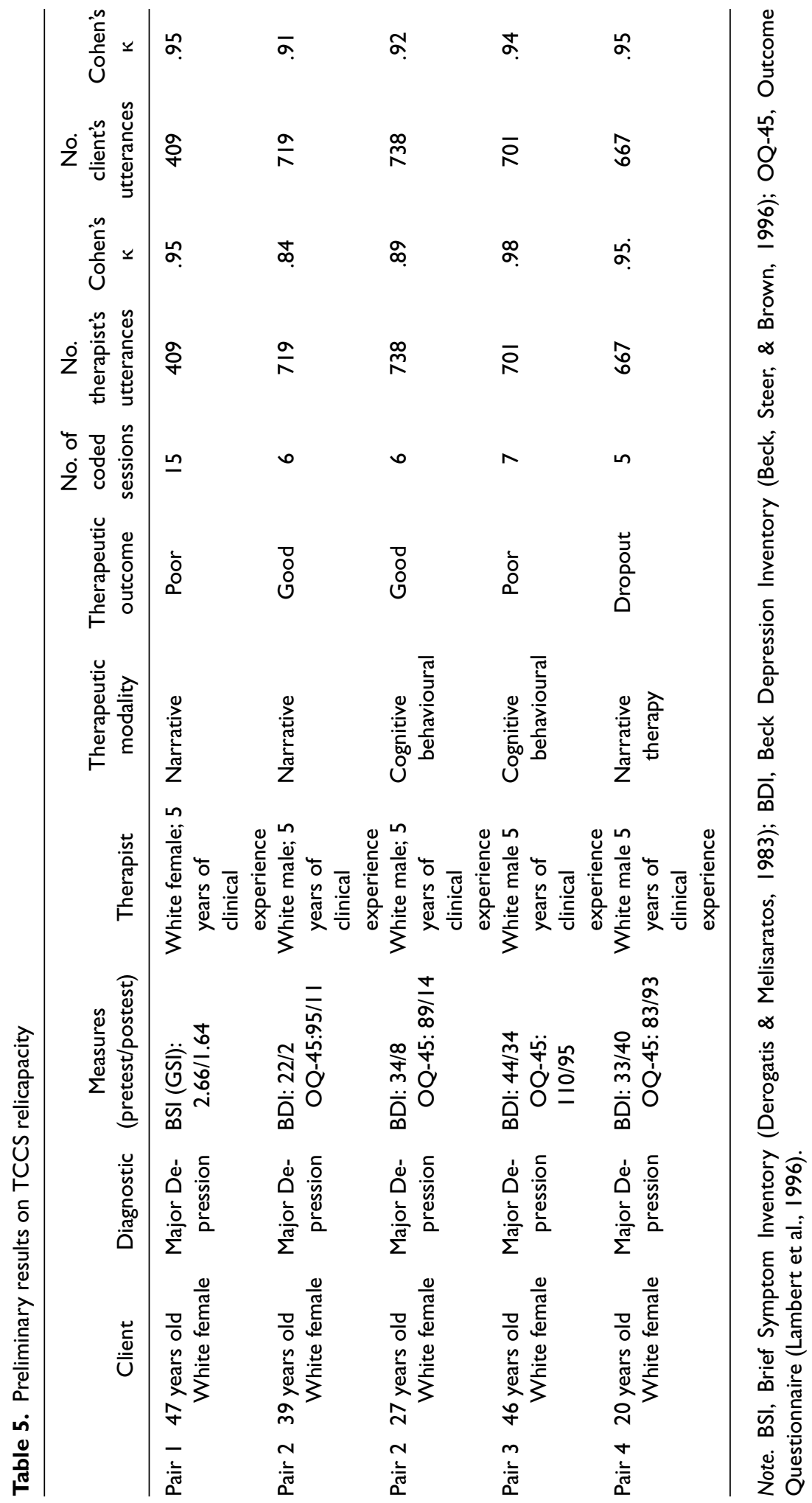




\section{Results}

This initial study showed a good reliability of the present version of TCCS, with mean Cohen's kappa values of .92 for therapist interventions (ranging from .84 to .98; based on $N=3,234$ utterances) and .93 for client responses (ranging from .91 to .95; based on $N=3,234$ utterances); see Table 5. It appears that our initial trial, the TCCS has showed acceptable reliability.

\section{Conclusion}

The goal of our research programme was to develop an understanding of how the relationship between therapist and client in general, and the collaboration in particular, contributes to clients' growth and development in therapy. We began by articulating an integrative theoretical framework that utilized the concepts of TZPD (Vygotsky, 1978; Leiman \& Stiles, 2001), the assimilation model of therapeutic gains (Stiles, 2011), and Gonçalves' narrative concept of IMs. (Gonçalves et al., 2009).

Our model integrates the role of the relationship element and techniques by conceptualizing the process of therapeutic progress as a cyclical and dynamic collaboration between therapist and client in which the therapist attempts to balance the clients need for safety with the goal of exploring novel, innovative versions of his or her self-narratives within the TZPD. We see the negotiation of the limits of the TZPD as fluid and dynamic since the clients tolerance for the anxiety provoked by challenging the upper boundary of the TZPD is limited and limiting; but each episode of novel conceptualization of self (IM) has the potential of moving the TZPD forward.

To observe and monitor these moment-to-moment dynamics, we developed the TCCS. TCCS is based on an intensive analysis of both good and poor outcome therapies treated by therapists with narrative or CBT orientation. The TCCS can be used to analyse therapist-client interaction sequences in context. We identified 15 possible interactive sequences corresponding to six possible positions the therapeutic dyad might be located, considering the TZPD. Fourteen of these 15 positions have been corroborated in the data reported in this study. Preliminary results indicate that the instrument has adequate reliability for research use.

We believe that the TCCS could be useful in qualitative studies, for instance, in combination with the significant events paradigm (Rice \& Greenberg, 1984), examining how significant events, such as alliance ruptures and resolution, unfold sequentially within the collaborative therapeutic interaction. It could also be used in quantitative studies using indexes that can be computed from the coding, such as the frequency or percentage of exchanges within the TZPD, at the limit of the TZPD, or outside of the TZPD. Such indexes could assess the evolution of therapeutic collaboration within single sessions or across whole treatments.

While the TCCS was developed as a research tool, we think that if future studies confirm our initial results, it might be useful for training since it could be used to help sensitize trainees to better locate the TZPD within which the potential of therapeutic gains may be maximized. Likewise it might, with further validation and development, serve as a diagnostic tool to identify challenges that are miss timed or too threatening for clients, as well as situations where there are unutilized opportunities for more challenging exploration.

Some of the limitations inherent in the current stage of our research include the limits that the number of different therapeutic orientations we have explored so far, 
one of the 15 positions have not been instantiated in a clinical sample, and we have yet to confirm that ratings of similar accuracy and reliability can be achieved outside our research programme.

\section{Acknowledgement}

This work was supported by the Portuguese Foundation for Science and Technology (FCT); the PhD Grant SFRH/BD/46189/2008.

\section{References}

Alen, J. G., Fonagy, P., \& Bateman, A. W. (2008). Mentalizing in clinical practice. London: American Psychiatric Publishing, Inc.

Arkowitz, H., \& Engle, D. (2007). Understanding and working with resistant ambivalence in psychotherapy. In S. G. Hofmann \& J. Weinberg (Eds.), The art and science of psychotherapy (pp. 171-190). New York: Routledge.

Beck, A. T., Steer, R. A., \& Brown, G. K. (1996). Manual for the Beck Depression Inventory-II. San Antonio, TX: Psychological Corporation.

Boardman, M. P. H., Catley, D., Grobe, J. E., Litle, T., \& Ahlumalia, J. S. (2006). Using motivational interviewing with smokers: Do therapist behaviors relate to engagement and therapeutic alliance? Journal of Substance Abuse Treatment, 31, 329-339.

Brinegar, M. G., Salvi, L. M., Stiles, W. B., \& Greenberg, L. S. (2006). Building a meaning bridge: Therapeutic progress from problem formulation to understanding. Journal of Counseling Psychology, 53, 165-180. doi:10.1037/0022-0167.53.2.165

Caro Gabalda, I., \& Stiles, W. B. (2009). Retrocessos no contexto de terapia linguística de avaliação [Setbacks in the context of linguistic therapy of evaluation]. Análise Psicológica, 27, 199-212.

Caro Gabalda, I., \& Stiles, W. B. (2012). Irregular assimilation progress: Setbacks in the context of Linguistic Therapy of Evaluation. Manuscript submitted for publication.

Colli, A., \& Lingiardi, V. (2009). The Collaborative Interactions Scale: A new transcript-based method for the assessment of therapeutic alliance ruptures and resolutions in psychotherapy. Psychotherapy Research, 19(6), 718-734. doi:10.1080/10503300903121098

Derogatis, L. R., \& Melisaratos, N. (1983). The Brief Symptom Inventory: An introductory report. Psychological Medicine, 13, 595-605.

Dimaggio, G., Carcione, A., Salvatore, G., Semerari, A., \& Nicolò, G. (2010). A rational model for maximizing the effects of therapeutic relationship regulation in personality disorders with poor metacognition and over-regulation of affects. Psychology and Psychotherapy: Theory, Research and Practice, 83, 363-384. doi:10.1348/147608310X485256

Dimaggio, G., Carcione, A., Salvatore, G., Sisto, A., Nicolò, G., \& Semerari, A. (2011). Progressively promoting metacognition in a case of obsessive-compulsive personality disorder treated with metacognitive interpersonal therapy. Psychology and Psychotherapy: Theory, Research and Practice, 84, 70-83. doi:10.1348/147608310X527240

Ecker, B., \& Hulley, L. (2000). The order in clinical disorders: Symptom coherence in depthoriented brief therapy. In R. A. Neimeyer \& J. D. Raskin (Eds.), Construction of disorder: Meaning-making self-narratives for psychotherapy (pp. 63-89). Washington, DC: American Psychological Association.

Engle, D., \& Arkowitz, H. (2008). Viewing resistance as ambivalence: Integrative strategies for working with ambivalence. Journal of Humanistic Psychology, 48, 389-412. doi: $10.1177 / 0022167807310917$

Engle, D., \& Holiman, M. (2002). A gestalt-experiential perspective on resistance.JCLP/In Sessions: Psychotherapy in Practice, 58, 175-183. doi:10.1002/jclp.1141

First, M. B., Spitzer, R. L., Gibbon M., \& Williams, J. B. W. (1996). Structured Clinical Interview for DSM-IV Axis I Disorders, Clinician Version (SCID-CV). Washington, DC: American Psychiatric Press, Inc. 
Fonagy, P., Bateman, A., \& Bateman, A. (2011). The widening scope of mentalizing: A discussion. Psychology and Psychotherapy: Theory, Research and Practice, 84, 98-110. doi:10.1111/j.2044-8341.2010.02005.x

Gonçalves, M. M., Matos, M., \& Santos, A. (2009). Narrative therapy and the nature of "innovative moments" in the construction of change. Journal of Constructivist Psychology, 22, 267-294. doi:10.1080/10720530802500748

Gonçalves, M. M., Mendes, I., Ribeiro, A. P., Angus, L., \& Greenberg, L. (2010). Innovative moments and change in emotional focused therapy: The case of Lisa. Journal of Constructivist Psychology, 23, 267-294. doi:10.1080/10720537.2010.489758

Gonçalves, M. M., \& Ribeiro, A. P. (2012). Narrative processes of innovation and stability within the dialogical self. In H. J. M. Hermans \& T. Gieser (Eds.), Handbook of Dialogical Self Theory (pp. 310-318). Cambridge: Cambridge University Press.

Gonçalves, M. M., Ribeiro, A. P., Conde, T., Matos, M, Santos, A., Martins, C., \& Stiles, W. B. (2011). The role of mutual in-feeding in maintaining problematic self-narratives: Exploring one path to therapeutic failure. Psychotherapy Research, 21, 27-40. doi:10.1080/10503307.2010.507789

Gonçalves, M. M., Ribeiro, P. A., Mendes, I., Matos, M., \& Santos, A. (2011). Tracking novelties in psychotherapy process research: The innovative moments coding system. Psychotherapy Research, 21, 497-509. doi:10.1080/10503307.2011.560207

Gonçalves, M. M., \& Stiles, W. B. (2011). Introducing the special section on narrative and psychotherapy. Psychotherapy Research, 21, 1-3. doi:org/10.1080/10503307.2010.534510

Hatcher, R. (1999). Therapists' views of treatment alliance and collaboration in therapy. Psychotherapy Research, 9(4), 405-423. doi:10.1080/10503309912331332831

Hatcher, R. L., \& Barends, A. W. (2006). How a return to theory could help alliance research. Psychotherapy: Theory, Research, Practice, Training, 43(3), 292-299. doi:10.1037/00333204.43.3.292

Hill, C. E., Knox, S., Thompson, B. J., Williams, E. N., Hess, S. A., \& Ladany, N. (2005) Consensual qualitative research: An update. Journal of Counseling Psychology, 52(2), 196-205. doi:10. 1037/0022-0167.52.2.196

Horvath, A. O., \& Bedi, R. (2002). The alliance. In J. Norcross (Ed.). Psychotherapy relationships that work: Therapist contributions and responsiveness to patients (pp. 37-69). Oxford: Oxford University Press.

Horvath, A. O., Del Re, A., Flückiger, C., \& Symonds, B. D. (2011). Alliance in individual psychotherapy. In J. C. Norcross (Ed.), Psychotherapy relationships that work (2nd ed., pp. 25-69). New York: Oxford University Press.

Horvath, A. O., \& Symonds, B. D. (1991). Relation between working alliance and the outcome in psychotherapy: A meta-analysis. Journal of Counseling Psychology, 38, 139-149.

Kelly, G. (1955). The psychology of personal constructs (Vol. 1). New York: Routledge.

Lambert, M. L. (Ed.) (2004). Bergin and Garfield's handbook of psychotherapy and behavior change (5th ed.). New York: Wiley.

Lambert, M. J., Burlingame, G. M., Umphress, V. J., Hansen, N. B., Vermeersch, D., Clouse, G., \& Yanchar, S. (1996). The relicapacity and validity of the Outcome Questionnaire. Clinical psychology and Psychotherapy, 3, 106-116.

Leiman, M., \& Stiles, W. B. (2001). Dialogical sequence analysis and the zone of proximal development as conceptual enhancements to the assimilation model: The case of Jan revisited. Psychotherapy Research, 11, 311-330.

Lepper, G., \& Mergenthaler, E. (2005). Exploring group process. Psychotherapy Research, 15(4), 433-444. doi:10.1080/10503300500091587

Lepper, G., \& Mergenthaler, E. (2007). Therapeutic collaboration: How does it work?. Psychotherapy Research, 17(5), 576-587. doi:10.1089/10503300601140002

Lepper, G., \& Mergenthaler, E. (2008). Observing therapeutic interaction in the "Lisa" case, Psychotherapy Research, 18(6), 634-644. doi:10.1080/10503300701442001

Liotti, G., \& Gilbert, P. (2011). Mentalizing, motivation, and social mentalities: Theoretical considerations and implications for psychotherapy. Psychology and Psychotherapy: Theory, Research and Practice, 84, 9-25. doi:10.1348/147608310X520094 
Mahoney, M. J. (1991). Human change processes: The scientific foundations of psychotherapy. New York: Basic Books.

McAdams, D. P. (2001). The psychology of life stories. Review of General Psychology, 5(2), 100-122. doi:10.1037/1089-2680.5.2.100

Mergenthaler, E. (1996). Emotion-abstraction patterns in verbatim protocols: A new way to describing psychotherapeutic processes. Journal of Consulting and Clinical Psychology, 64, 1306-1315. doi:10.1037/0022-006x.64.6.1306

Norcross, J. C. (2002). Empirically supported therapy relationships. In J. C. Norcross (Ed.), Psychotherapy relationships that work (pp. 3-16). New York: Oxford University Press.

Norcross, J. C. (2010). The therapeutic relationship. In B. L. Ducan, S. D. Miller, B. E. Wampold, \& M. A. Hubble (Eds.), The heart and soul of change (pp. 113-142). Washington, DC: American Psychological Association.

Norcross, J. C., \& Goldfried, M. (Eds.). (2005). Handbook of psychotherapy integration (2nd ed.). New York: Oxford University Press.

Osatuke, K., Glick, M. J., Gray, M. A., Reynolds, D. J., Jr., Humphreys, C. L., Salvi, L. M., \& Stiles, W. B. (2004). Assimilation and narrative: Stories as meaning bridges. In L. Angus \& J. McLeod (Eds.), Handbook of narrative and psychotherapy: Practice, theory, and research (pp. 193-210). Thousand Oaks, CA: Sage.

Ribeiro, A. P., Bento, T., Salgado, J., Stiles, B., \& Gonçalves, M. M. (2011). A dynamic look at narrative change in psychotherapy: A case-study using the State-Space Grids. Psychotherapy Research, 21, 54-69. doi:10.1080/10503307.2010.504241

Ribeiro, A. P., \& Gonçalves, M. M. (2010). Innovation and stability within the dialogical self: The centrality of ambivalence. Culture \& Psychology, 16(1), 116-126. doi:10.1177/135067X09353211

Rice, L. N., \& Greenberg, L. S. (1984). The new research paradigm. In L. N. Rice \& L. S. Greenberg (Eds.), Patterns of change: Intensive analysis of psychotherapy process (pp. 7-25). New York: Guilford.

Sacks, H., Schegloff, E. A., \& Jefferson, G. (1974). A simplest systematic for the organization of turn-taking in conversation. Language, 50(4), 696-735.

Safran, J. D., \& Muran, J. C. (2000). Negotiating the therapeutic alliance, a relational treatment guide. New York: Guilford Press.

Safran, J. D., \& Muran, J. C. (2006). Has the concept of the therapeutic alliance outlived its usefulness? Psychotherapy: Theory, research, practice, training, 43(3), 286-291. doi:10.1037/ 0033-3204.43.3.286

Stiles, W. B. (2001). Assimilation of problematic experiences. Psychotherapy, 38, 462-465. doi:10.1037/0033-3204.38.4.462

Stiles, W. B. (2011). Coming to terms. Psychotherapy Research, 21, 367-384. doi:10.1080/10503307.2011.582186

Tracey, T. J. (1993). An interpersonal stage model of the therapeutic process. Journal of Counseling Psychology, 40, 396-409.

Tyron, G. S., \& Winograd, G. (2002). Goal consensus and collaboration. In J. C. Norcross (Ed.), Psychotherapy relationships that work (pp. 109-128). New York: Oxford University Press.

Vygotsky, L. (1978). Mind in Society: the development of higher psychological processes. Cambridge, MA: Harvard University Press.

Wampold, B. E. (2001). The Great psychotherapy debate: Models, methods, and findings. Mahwah, NJ: Erlbaum.

Westerman, M. A. (1998). Curvilinear trajectory: Patient coordination over the course of short term therapy. Psychotherapy: Theory, Research, Practice, Training, 35, 206-219. doi: $10.137 / 40087652$

White, M., \& Epston, D. (1990). Narrative means to therapeutic ends. New York: Norton.

Received I8 March 201 I; revised version received 2I February 2012 